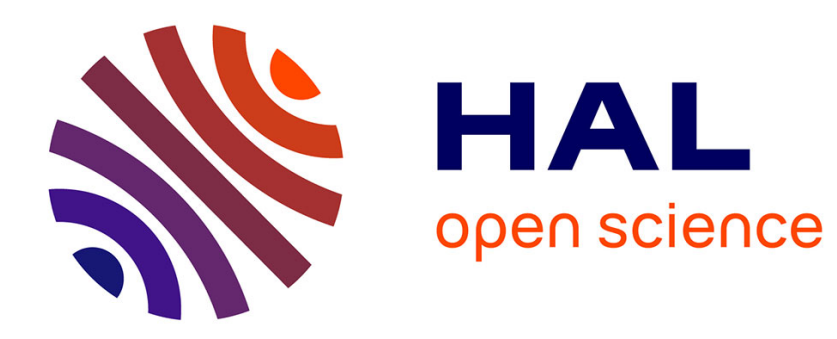

\title{
Thin films and architectural glass
}

B. Buffat

\section{- To cite this version:}

B. Buffat. Thin films and architectural glass. Journal de Physique IV Proceedings, 1992, 02 (C2), pp.C2-11-C2-19. 10.1051/jp4:1992202 . jpa-00251273

\section{HAL Id: jpa-00251273 https://hal.science/jpa-00251273}

Submitted on 1 Jan 1992

HAL is a multi-disciplinary open access archive for the deposit and dissemination of scientific research documents, whether they are published or not. The documents may come from teaching and research institutions in France or abroad, or from public or private research centers.
L'archive ouverte pluridisciplinaire HAL, est destinée au dépôt et à la diffusion de documents scientifiques de niveau recherche, publiés ou non, émanant des établissements d'enseignement et de recherche français ou étrangers, des laboratoires publics ou privés. 


\title{
Thin films and architectural glass
}

\author{
B. BUFFAT
}

Saint-Gobain Recherche, 39 Quai Lucien Lefranc, 93303 Aubervilliers Cedex, France

\begin{abstract}
The use of thin films in the flat glass industry is growing steadily. In this paper, after a brief description of the pyrolytic and magnetron sputtering deposition techniques, a survey is presented of the essential film designs which have been developped by glass manufacturers to improve their products in the field of architectural glazings.
\end{abstract}

\section{1) INTRODUCTION}

Thin films and architectural glass have both been known for a long time. Our ancestors in prehistoric times used to sharpen their tools and weapons in a flame without knowing that they were probably coating them with a hard carbon film. More recently highly reflective solid thin film coatings were obtained by Venitians in the $16^{\text {th }}$ century after the discovery of a method of amalgamating tin foil and mercury on glass. On the other hand, the first known window was found in Pompei and window-glass started to become a widespread product after the XVIIth century.

In spite of these very early developments, it is only over the past 30 years that thin films have been used to enhance the thermal performance of window glazings and to afford a new dimension in the aesthetic aspects of building design. Before that time, glass manufacturers had made significant advances through the development of double glazings and tinted heat absorbing glasses. The performance of such products is however limited. It is with the development of large-scale glass-coating facilities in the 1960's that architectural coatings really became economically significant and experienced considerable expansion.

There exist two main categories of deposition techniques for the production of architectural films on glass : vacuum deposition methods (essentially sputtering) and thermo-chemical methods (spray or powder pyrolysis, CVD or dip-coating) and these techniques do not differ fundamentally from the techniques which are used in the general field of thin films. Their specificity comes from the fact that demands on the thickness of the films, durability requirements - due to the varied and often severe conditions of exposure and to the lifetime expected for architectural products - and quantities and surface areas involved require large-scale deposition equipements and rather specialized process methods. 


\section{2) DEPOSITION TECHNIQUES}

\section{1 - Flat Glass}

Flat glass is a product for the general public and its markets (construction, automobile, electronics) are dependent on world population. The glass industry is therefore a heavy industry with factories producing up to 15 to 20 million square meters of glass each year. It is a cheap product (with a price equivalent to that of potatoes at about $5 \mathrm{~F} / \mathrm{kg}$ ), which is nevertheless long-lasting (ten year guarantee for the construction industry in France) and of constant quality.

The functions of glazings can be modified by applying thin films while still maintaining the characteristics required for a widely used product that is :

- high rates of production,

- moderate cost (comparable with that of the glass substrate),

- durability : these layers must be resistant to abrasion, chemical corrosion (air, rain including acid rain, detergents, adhesives and sealants...), thermal cycles (day/night, winter/summer) and solar radiation.

In fact, these films should ideally withstand the industrial operations (tempering, bending, cleaning, drying...), which are necessary in the processing of the more elaborate glass products for the construction or automobile industries.

\section{2 - Pyrolytic processes}

This presentation will be limited to pyrolytic processes which are used on the continuous float glass production lines.

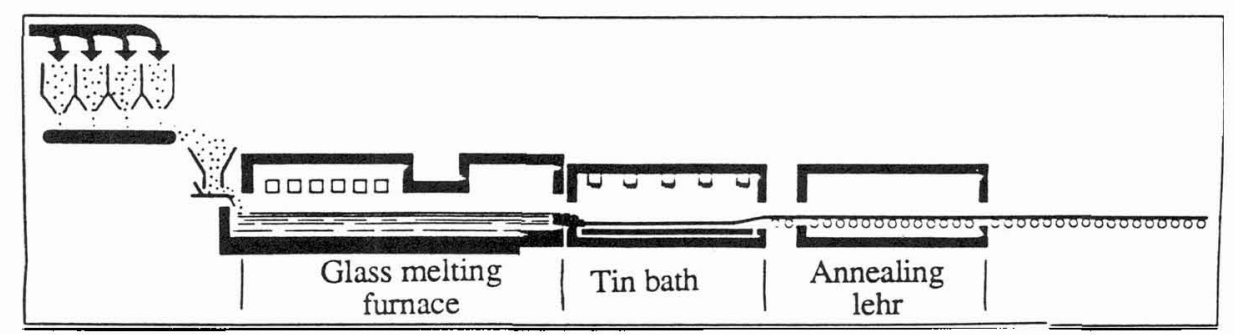

Figure 1 : Basics of a float line

A float line consists in :

- a zone of fusion for the melting, homogenization and "refining" of the mixture of raw materials,

- a zone of floating where the glass spreads over a bath of molten tin (between $1000^{\circ} \mathrm{C}$ and $600^{\circ} \mathrm{C}$ and in an atmosphere of nitrogen and hydrogen) forming a continuous sheet,

- a zone of controlled cooling from $600^{\circ} \mathrm{C}$ to room temperature, in order to prevent stresses from developing in the glass ribbon.

Pyrolysis installations can be added to the zone of floating, the zone of controlled cooling or in between. In these areas the glass is moving at a speed of 4 to 20 meters per minute. 


\section{Solid. liquid and gaseous pyrolysis}

Three types of pyrolysis are distinguishable according to the state of the raw material : layers,

- pyrolysis of solids, with a high deposition speed of $1 \mu \mathrm{m} / \mathrm{s}$, which can thus produce "thick"

- pyrolysis of solutions by spraying (diameter of the droplets : some tens of microns) or by atomizing (from an aerosol; diameter of the droplets : some microns),

- pyrolysis of vapours or "CVD" which gives deposition speeds in the order of $10 \mathrm{~nm} / \mathrm{s}$.

\section{Raw materials}

The raw materials used in the pyrolytic processes can be salts, organometallics, hydrides, etc... and may be dissolved in solvents. For solid pyrolysis the powders have to conform to specifications which concern:

- hygroscopy and toxicity (factors which are important for storage and security),

- granulometry (which influences the visual uniformity of the films as well as the accumulation of residues in the pyrolysis installation),

- impurities (which affect certain properties of the films such as optical and electrical performances, light diffusion, durability, etc...),

- yield of the pyrolysis (which is a factor in production costs).

\section{Systems of projection onto the glass}

The projection of pyrolyzable precursors onto hot glass is made through a fixed or a moving nozzle and poses delicate practical and theoretical problems. For example in order to reduce the accumulation of residues and to improve the visual uniformity of the film, it is necessary to study theories of flow in single and two phase systems. At the same time, the distribution of the temperatures close to and on the glass surface has to be carefully controlled to prevent "in flight" pyrolysis and to obtain films of uniform thickness. And finally, the composition of the atmosphere of pyrolysis is also an important factor which plays a role on the performances and appearance of the films.

\section{Effluents}

For the protection of the personnel and the environment, the by-products of the pyrolytic process require careful consideration and specific investigations. The evacuation and treatment of the effluents must be considered as an integral part of the process.

\section{3 - Sputtering}

Sputtering is at present the most frequently employed vacuum technique used to deposit thin films onto large sheets of glass. It consists of accelerating ions from a plasma in a partial vacuum towards a target having a negative potential (cathode) and made out of the material which is to be deposited. The positive ions bombard the target whose atoms are then vaporized in all directions and in particular towards the glass substrate where they condense in the form of a thin film. It is also possible to add a reactive gas to the plasma gas to obtain films other than of pure metal from the target : with oxygen, an oxide film is deposited, with nitrogen a nitride film etc...

The essential progress which has enabled the extension of this technology to be used on very large surfaces (a "standard" glass substrate is 6 meters long and 3 meters wide !) with the required rates of production is the use of a magnetic field created by placing permanent magnets behind the cathode. 
The magnetic field confines the secondary electrons emitted by the target to the area surrounding the target and thus reinforces the density of the plasma near the target and increases its sputtering speed. With modern installations, it is possible to produce uniform films on sheets of glass of up to 20 square meters with production rates exceeding 2 million square meters of coated glass per year.

The properties of a sputtered film depend on its thickness and structure which varies with several factors such as the substrate temperature or the residual gas pressure. If the vapour atoms have a low mobility on the substrate surface, three dimensional island growth during nucleation and coalescence stages is promoted : the film will then contain microvoids and exhibit a highly porous structure. This happens at low substrate temperatures and relatively high residual gas pressure (fig 2). If the pressure is lowered the film can experience a transition structure consisting of densely packed fibrous grains. Finally, high substrate temperature favour the crystallization of the films.

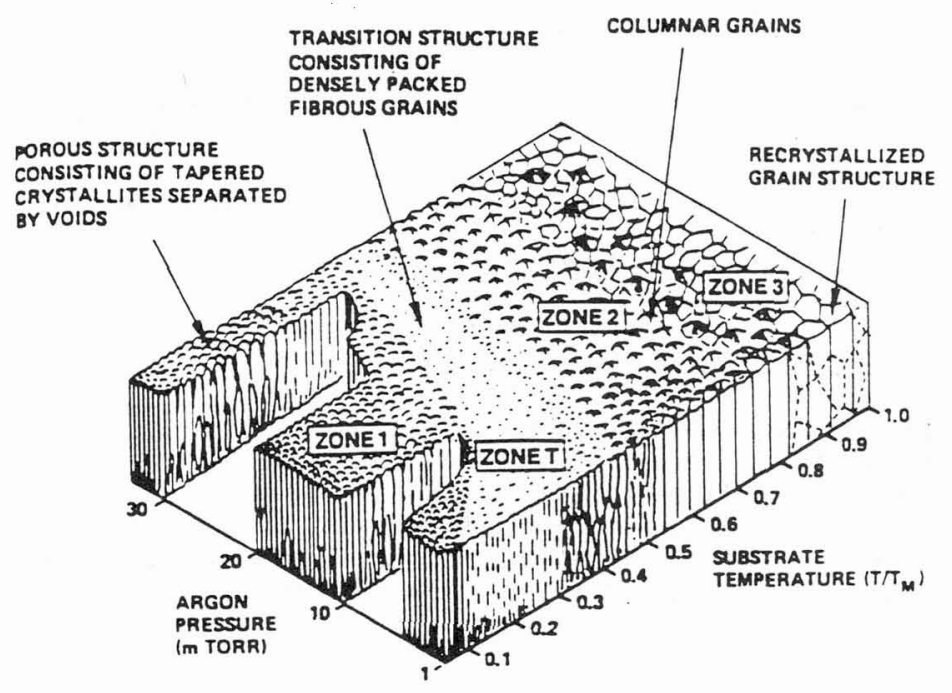

Figure 2 : Influence of substrate temperature and argon pressure on the microstructure of sputtered films (from ref. 1)

Compared to pyrolysis, sputtering appears as a very versatile process, enabling the deposition of numerous classes of compounds (metals, oxydes, nitrides, carbides, oxycarbides...) with precise control of the film microstructure. This versatility is however made costly by the fact that sputtering is an off-line process requiring more investment than pyrolysis lines which are often integrated into the float glass production line. Another important feature of sputtering is its high potentiality for complex multi-layer films whereas the possibilities of pyrolysis techniques are limited by the fact that the substrate is cooled by the process of deposition.

\section{3) THE USE OF THIN FILMS IN ARCHITECTURAL GLAZINGS}

There are basically three factors that must be considered in the design of an architectural coating, namely : - the human eye, characterized by its spectral sensitivity curve defining the visible spectrum (0.4 $0.7 \mu \mathrm{m}$ ), 
- the sun, acting as a high-temperature $(6000 \mathrm{~K})$ black body, whose radiation spectrum centered at $0.6 \mu \mathrm{m}$ covers a range from 0.3 to $2.2 \mu \mathrm{m}$,

- materials behind the window which act as room-temperature $(300 \mathrm{~K})$ black bodies and emit a radiation spectrum centered at $10 \mu \mathrm{m}$ and covering the range from 3 to $50 \mu \mathrm{m}$ (fig 3 ).

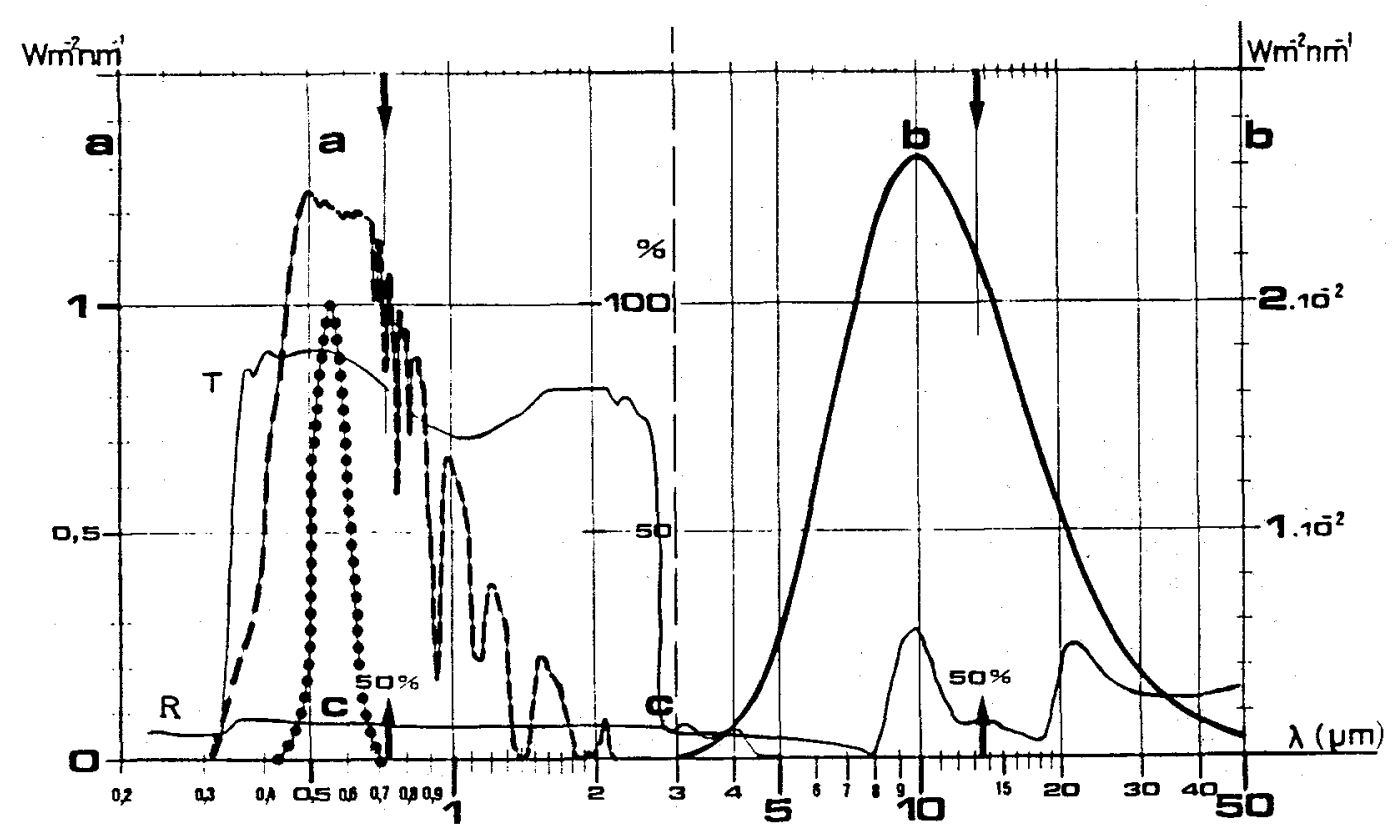

Figure 3 : Spectra for : a) solar irradiation on earth, b) black body radiation at $10^{\circ} \mathrm{C}, \mathrm{c}$ ) relative sensitivity of the human eye (photopic state), (T) transmittance of glass, $(R)$ reflectance of glass

The most remarkable property of standard soda-lime float glass is that it is transparent to the solar radiation and completely opaque to the ambiant thermal radiation spectrum. The average reflectivity is $8 \%$ in the visible ( $4 \%$ per face) and $15 \%$ per face in the thermal spectrum. Consequently, a glass surface facing air has a high emissivity $(\varepsilon=1-<\mathrm{R}>$ ) of approximately 0.85 .

These optical properties have both advantages and drawbacks. Glass is essentially appreciated for its transparence to visible radiation. But, in a hot climate, the high transmittance of the whole solar range often leads to overheating of buildings because all the energy transmitted inwards through the glass is then blocked (except a small part of it which is exchanged by conduction, convection or absorption and reemission). This is the "greenhouse effect".

On the other hand, in a very cold climate, windows are considered as sources of heat loss by conduction, convection and also radiation due to the high emissivity value of glass. Even if conduction and convection losses can be drastically diminished by the use of multiple glazings, the heat losses by radiation emittance remain and need to be decreased by using low-emissive coatings on glass.

In the visible spectrum, the reflection of a pane of glass is low but not null and this can be a problem for some specific applications like art framing and shop windows. 
Finally, in hot and even in temperate climates, there is a potential demand for glazings with variable transparency often called "smart-windows". We shall see in the following section how the use of thin films on glass can contribute to the solution of these different problems .

\section{$\underline{3.1 \text { - Solar control films }}$}

Solar control films are required in areas where the emphasis is on the high cooling requirements in summer months such as southern regions of Europe, US or Asia. Such coatings can vary considerably in degree of wavelength selectivity. However, they would ideally minimize the solar transmittance beyond $0.7 \mu \mathrm{m}$ (the long wavelength limit of the visible) and reduce visible transmittance to some intermediate level which would provide adequate illumination for daylight hours, yet limit total solar radiant load.

There are several different ways in which coatings can procure a decrease of the total solar transmittance of a glazing :

- an increase in the reflectance with a single layer of a high-index dielectric coating. This is the case for example of $\mathrm{TiO}_{2}$ films with a refractive index of 2.3 , which can be obtained either by sputtering or by liquid pyrolysis. Generally, the most important part of the effect is obtained in the visible range, i.e. the glazings obtained have poor selectivity.

- an increase in the absorption with a single layer of a highly absorbing film. Some interesting coatings of this type like nitrides or oxynitrides of titanium can be obtained by reactive sputtering. They allow a drastic reduction of the solar transmittance but have the drawback of being non selective (most of the energy absorption is obtained in the visible).

- a selective increase in the infrared reflectance using multilayer metal-dielectric coatings. Very thin noble-metal coatings are the simplest way to provide a significant short wavelength (visible) transmittance combined with a long wavelength (infrared) reflectance. The best materials are $\mathrm{Cu}, \mathrm{Ag}$ and $\mathrm{Au}$ and, among them, silver is prefered because of its low absorption of visible radiation Generally, these metal layers are included in a multilayer sandwich of the type $D / M / D /$ where $D$ is a dielectric layer whose fonctions are :

- as an under-layer, to promote silver nucleation,

- as an over-layer, to protect silver from corrosion and mechanical damage.

In spite of this, these metal multilayers can be used only in double glazings where they are only in contact with the dry air-filling.

\section{$\underline{3.2 \text { - Winter or cold climate films : low emissive coatings }}$}

An ideal winter or cold-climate film is one which has high reflectance and therefore low emittance for room temperature radiation, and maximum transmittance over the solar spectral range.

Such a coating actually enhances the green-house effect leading to improved comfort and lower heating costs in winter. The choice of coatings to meet these requirements is in fact practically restricted to two kinds of materials :

- extrinsic semi-conductors such as fluorine-doped tin oxide $\left(\mathrm{SnO}_{2}: \mathrm{F}\right)$ or indium tin oxide (ITO). $\mathrm{SnO}_{2}: \mathrm{F}$ for example is easily obtained by powder pyrolysis of certain organostannate compounds and the film obtained has typically an emissivity of 0.3 (compared to 0.85 for non-coated glass). Such a coating used in a double glazing can reduce the heat transfer coefficient to $2 \mathrm{~W} \mathrm{~m}^{-2} \mathrm{~K}^{-1}$ (compared to 6 for a single sheet of glass or 3 for a non-coated double glazing).

- multilayer silver-based systems.

Another class of winter or cold climate coatings can be obtained through multilayers having the structure dielectric/metal/dielectric. As for the solar control glazings, thin Ag coatings stand out as the prefered material on account of their low absorption in the visible. These multilayer systems are of the same general constitution as those already mentioned in section 3.1 for solar control films, but with lower metal 
thicknesses. Practically, this thickness is limited to a value just above the limit of coalescence of the metallic film. This value depends on the nature of the metal layers, the nature of the substrate on which the metal is coated as well as on the deposition technique and the process parameters. Typically, for magnetron sputtered silver layers, the thickness of around $10 \mathrm{~nm}$ which is used would produce a reflection that would lower the transmittance. However, a proper choice of the two dielectric layers can be made in order to chemically and mechanically protect the silver layer and, at the same time, act as antireflecting layers for the $\mathrm{Ag}$ film.

In all cases (oxide films or multi-layer silver based systems) the low emissive films are only efficient when the other sources of heat loss (conduction and convection) are reduced, i.e. in multiple glazings. A silver based film of the type described above, with an emissivity of 0.1 leads, in a double glazing, to a very low value of the heat transfer coefficient (1.7 compared to 6 for a single sheet of glass).

\section{$\underline{3.3-\text { Anti-reflection coatings }}$}

As pointed out earlier, each surface of a glass sheet produces $4 \%$ reflection, and this reflection can be undesirable in some specific applications like art framing, shop windows, etc...

A solution to this problem is to apply anti-reflection coatings which essentially consist of alternate layers of high and low index film of the type $\mathrm{TiO}_{2} / \mathrm{SiO}_{2}$. Only one commercial product from SCHOTT is at present on the market. It is obtained by sol-gel dipping, which has the great advantage of coating simultaneously the two faces of the glass sheet. The triple layer used has the the following structure :

$$
\text { glass } / \mathrm{TiO}_{2}+\mathrm{Al}_{2} \mathrm{O}_{3} / \mathrm{TiO}_{2} / \mathrm{SiO}_{2} \text {. }
$$

The main problem of these anti-reflecting coatings for out-door applications is that the coating has to be applied on all faces (including the outside) and its resistance to corrosion and abrasion has to be as good as that of uncoated glass.

\section{4 - Liquid-crystal and electrochromic systems}

Finally, there exists a potential demand for glazings with variable transparency, in other words for "smart windows". In principle, photochromic or thermochromic materials would appear to provide the simplest and most attractive solutions. Unfortunately, no system known at present combines the required life-time with sufficient darkening at the temperatures that can be expected in direct sunlight.

In fact, two classes of materials are intensively studied, with complementary applications :

- internal partitioning glazings based on polymer-dispersed liquid crystals can be commuted electrically between transparent and translucent states, which allows privacy to be obtained instantaneously without the need of curtains or blinds. These glazings are obtained from a transparent polymer matrix in which micro-droplets of a nematic liquid crystal have been dispersed, and which is sandwiched into two sheets of glass or plastic covered with a transparent conducting film (Fig.4). The liquid crystal molecules have an "ordinary" refractive index no perpendicular to their symmetry axis and an "extraordinary" refractive index $n_{e}$ parallel to this axis. The polymer matrix is conveniently chosen with an index $n_{p}$ close to $n_{\mathrm{o}}$. When the system is unpolarized, the optical axes of the different droplets are randomly distributed and the system is light diffusive. Under tension, the optical axes of all the droplets become parallel to the electric field, the incident light falls on a continuous medium of index $n_{p}=n_{o}$ and the system becomes transparent. 

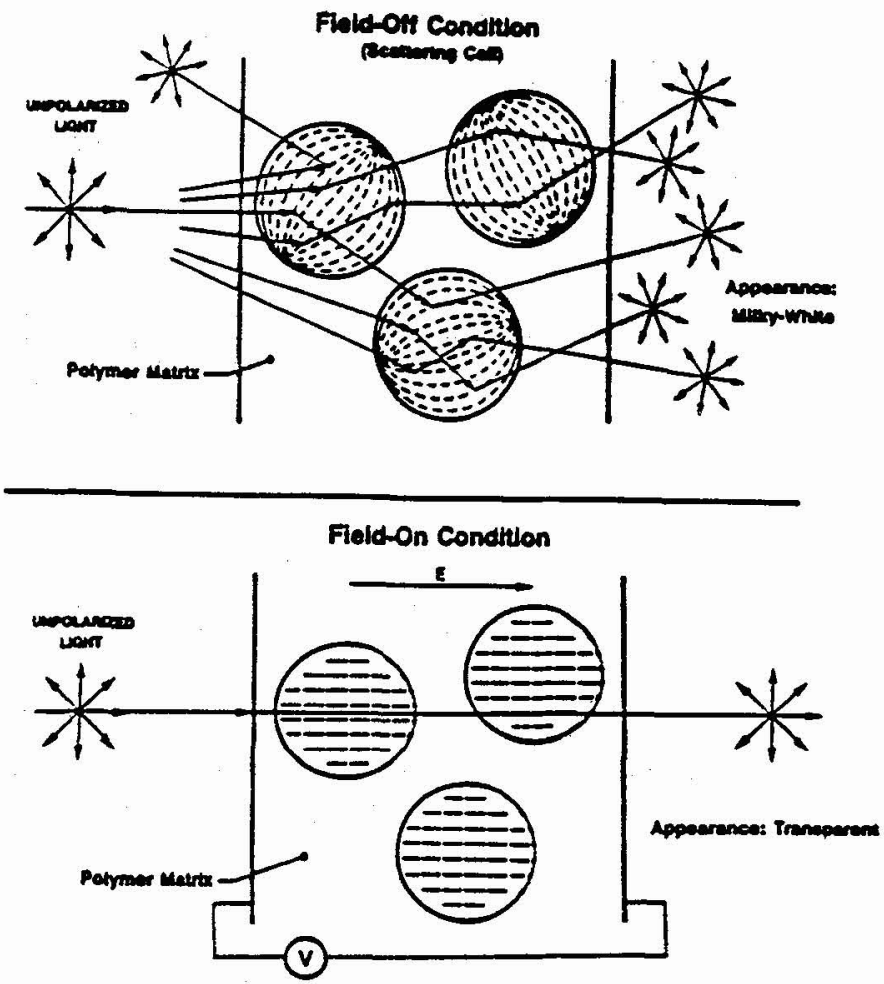

Figure 4 : Principle of a polymer-dispersed liquid crystal device

- Electrochromic systems on the other hand will in the future be used to provide a dynamic throughput of radiant energy into buildings. Most of these systems are based on the property of certain transition metal oxides (like tungsten oxide $\mathrm{WO}_{3}$ ) to reversibly change colour with the injection or the extraction of mobile ions (2). An electrochromic glazing generally comprises two outer transparent conductors required for setting up an electric field, an electrochromic layer, an ion conductor and an ion storage layer (Fig.5). Coloration (or bleaching) is obtained when ions are moved from (or to) the ion storage electrode, via the ion conductor, into (or out of) the electrochromic layer.

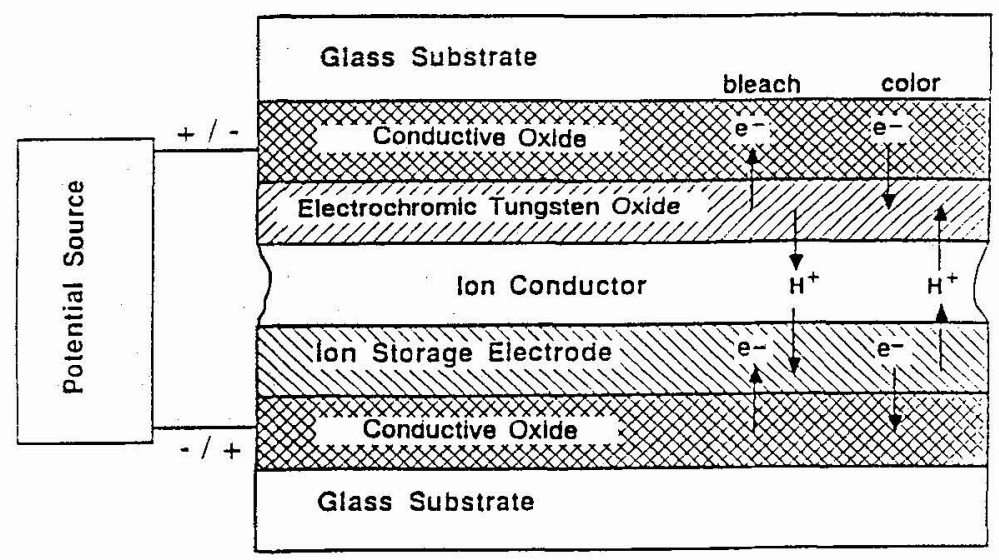

Figure 5 : Basic design of an electrochromic device 
These systems lead to a variation of the visible transmittance from high $(70 \%)$ to low $(<10 \%)$ levels. Moreover, all the intermediate states are obtainable by simply turning off the power supply. Thus, the natural lighting can be precisely chosen to the required level depending on outside conditions. These systems are also efficient in the solar infrared range and can also, in principle, be used to regulate the amount of solar heat transmitted to the building. These systems are still at a research and development stage notably on account of the problem of ageing at high temperatures. However, constant progress is being made and they may be considered as glazings of the future.

\section{CONCLUSION}

With the continuing development of materials and of deposition processes replying to increasing demands for glazings with properly controlled visual and thermal properties, thin films and architectural glass will become more and more inter-related. Architectural coatings, from the very simplest reflecting glass to the more sophisticated smart-windows will certainly have a prominent role to play in future design and construction of buildings of all types.

(1) P.J. MARTIN, J. Materials Science, Vol.21, 1-25 (1986)

(2) B. BUFFAT and F. LERBET, La Recherche, Vol.231, 434-442 (1991) 